\title{
Airborne spread of SARS-CoV-2 while using high-flow nasal cannula oxygen therapy: myth or reality?
}

Andrew Haymet ${ }^{1,2}$, Gianluigi Li Bassi ${ }^{1,2,3^{*}}$ (1) and John F. Fraser ${ }^{1,2}$

๑ 2020 Springer-Verlag GmbH Germany, part of Springer Nature

In 2020, a new pandemic caused by SARS-CoV-2 was declared [1], and since the first cases of coronavirus disease 2019 (COVID-19), clinicians had to apply different modes of respiratory support, previously used on patients with severe respiratory failure from other etiologies. In particular, high-flow nasal cannulae (HFNC) and non-invasive ventilation (NIV) were variably applied in early reports from China [2] and Europe [3]. Yet, the extent of airborne contamination of clinical areas during the use of HFNC has sparked intense debate and highlighted the need for inclusive investigation in this area.

SARS-CoV-2 may be spread by direct or indirect contact with infected individuals through respiratory secretions or droplet transmission, as well as through fomites [4]. Once airborne, the half-life of SARS-CoV-2 is approximately one hour [95\% credible interval, 0.64 to 2.64] [5]. Airborne transmission was initially underestimated; indeed in one analysis in February 2020 of 75,465 cases in China, airborne transmission was not reported [6]. A later study by Liu et al. from Wuhan analyzed aerosol samples using droplet digital polymerase chain reaction, and concluded that virus aerosol deposition on protective apparel or floor surface and their subsequent re-suspension was a conceivable transmission pathway [7]. These findings were further corroborated by Santarpia et al. on 13 isolated patients, who concluded that transmission may occur via contaminated objects and airborne transmission, as well as direct transmission via droplets [8]. Several other factors modulate the specific

\footnotetext{
*Correspondence: g.libassi@uq.edu.au

${ }^{2}$ Critical Care Research Group, The Prince Charles Hospital, Clinical Science Building, 627 Rode Rd, Chermside, QLD 4032, Australia

Full author information is available at the end of the article
}

risk of healthcare workers (HCW) of being infected with SARS-CoV-2 and could be grouped into patient-related and HCW-related risk factors. Patient-related risks are associated with the volume and distance of respiratory particles generated and mobilized from the patient, the viral titre and long-term viability within the aerosolized particles, and finally the ability of the virus to penetrate innate host defenses. In contrast, HCW-related factors are associated to the HCW's health status, comorbidities and immunocompetency, the length of time of exposure and adequacy of worn personal protective equipment (PPE). Patients with COVID-19 often present to the emergency department with substantial respiratory drive and persistent dry cough. Thus, based on the aforementioned evidence, viral transmission from respiratory particles and droplet dispersion may theoretically pose a significant risk to $\mathrm{HCW}$, specifically in patients who are undergoing means of ventilatory support without shielding their mouths, and during the early days of hospital admission, when the viral load is the highest [9].

Unfortunately, to date, the literature describing risks of airborne contamination by HFNC versus other means of support, i.e. NIV via face mask or helmet or nose mask, is heavily reliant on preclinical data, not specifically focused on SARS-CoV-2, and thus is inducing rather than answering controversy in the field (Table 1). In an important preclinical study by Gaeckle and collaborators [10], particle concentration and size from the respiratory tract of 10 healthy individuals receiving oxygen with various modes of delivery were measured through an aerodynamic particle spectrometer. Importantly, no increase in the concentration of aerosols generated was found with the use of HFNC or NIV when compared with breathing room air or non-humidified oxygen modalities. However,

\section{Springer}



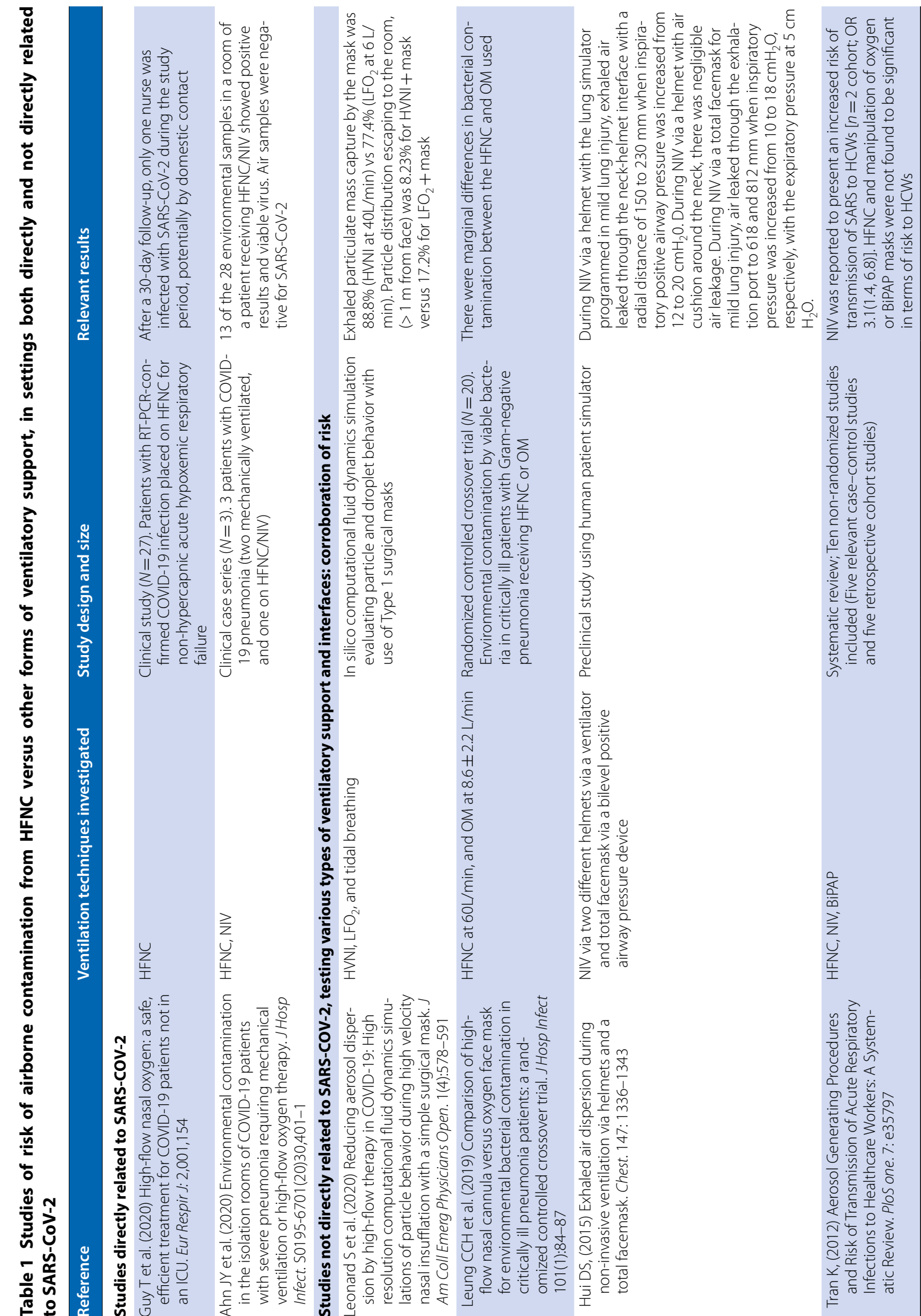


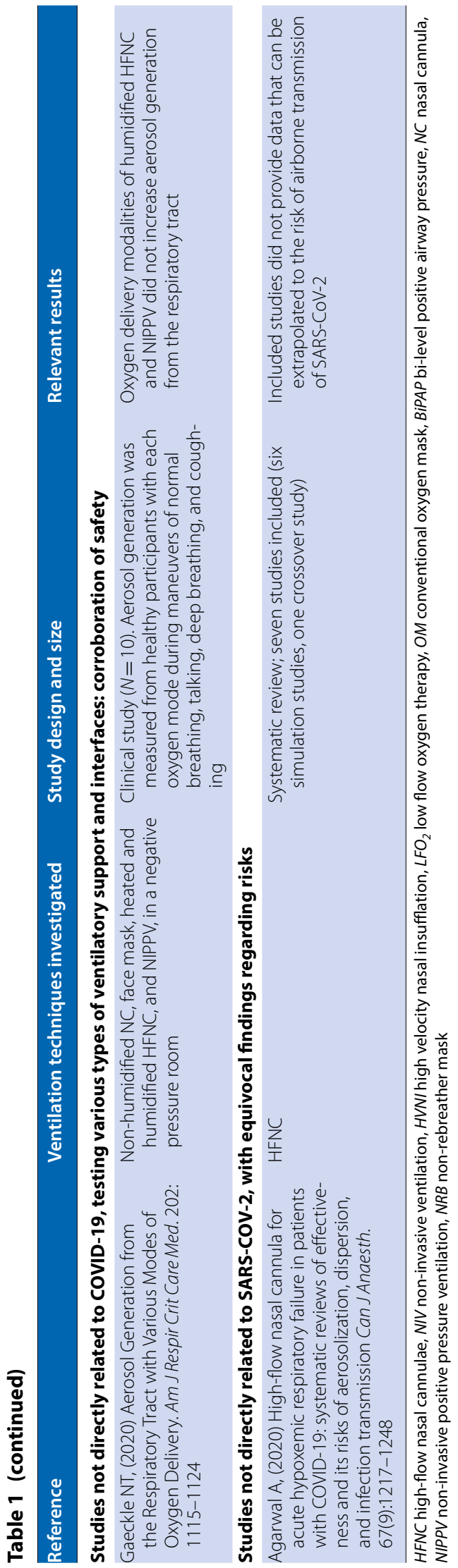

it should be noted that this was a small study in healthy participants, without ongoing pulmonary disease, which limits extrapolations to patients infected by SARS-CoV-2. Indeed, these results were also contingent upon the method of sampling aerosolized particles, which in itself carries risk of sampling error. Furthermore, consistent results suggest that fitting of HFNC or NIV interfaces, i.e. nasal pillow/mask or face mask, plays a crucial role in droplet generation. In a study by Hui et al.[11], conducted on a human patient simulator of dispersion of traceable particles, the authors concluded that exhaled air dispersion was higher using NIV and dependent on the applied settings, as corroborated by substantial increases in dispersed air when NIV pressure was increased from 5 to $20 \mathrm{cmH}_{2} \mathrm{O}$ or HFNC flow from 10 to $60 \mathrm{~L} / \mathrm{min}$. However, the highest dispersion was found by loosening the HF nasal cannulas or the HF oxygen circuit tube [11]. Tran et al.[12] studied the transmission of SARS from patients undergoing ventilatory support to $\mathrm{HCW}$. They found that the virus could be dispersed through NIV, but not from HFNC or BiPAP mask adjustment. The study was limited by the small population and questionable methodology, and further emphasized the current lack of systematic appraisal of airborne viral transmission from infected patients. Finally, an in silico computational fluid dynamics simulation by Leonard et al. showed that using a simple surgical mask over the HFNC interface is effective in reducing distribution of aerosolized particles [13].

In the setting of SARS-CoV-2, evidence on this subject is highly limited and anecdotal. Various investigators have suggested that HFNC and NIV are associated with proven aerosolization of viable virus particles around the patient bedspace, but failed to establish a clear association with an increased number of HCW infections. To illustrate, one clinical study demonstrated that distribution of viable virus particles throughout the immediate clinical environment occurred with HFNC and NIV [14]. A separate clinical study showed that when staff were fully trained in the use of PPE, the rate of $\mathrm{HCW}$ infection whilst being in the immediate vicinity of HFNC was extremely low [15]. More high-quality evidence is clearly needed to better establish the true risk of infection to HCWs from aerosolization. For HFNC, the continued perception of a risk of viral aerosolization remains a significant obstacle to its uptake for management of hypoxemic respiratory failure in COVID-19, as highlighted by discordant recommendations on its use from health organizations and medical societies across the globe. Nevertheless, potential risks should be balanced with the described benefits with the use of HFNC, even in COVID-19 patients in the prone position.

Taken together, airborne contamination via generation of aerosols during HFNC must at this stage be assumed 
as conceivable and potentially perilous to the $\mathrm{HCW}$, until proven otherwise. Preclinical data, whilst useful to establish the mechanics of aerosolization, unfortunately do not capture the endpoint of absolute risk, which ultimately depends on the quantity and viability of pathogenic material and specific $\mathrm{HCW}$ risks. In the meanwhile, reducing dispersion through simple measures, such as surgical masks and careful fitting of the interfaces and sealing of the circuit on supported patients are strongly recommended. Further clinical research, and particularly systematic human studies, which can correlate the degree of ventilation-dispersed aerosols with the quantity and viability of dispersed virulent particles that are capable of causing infection, are urgently required.

\footnotetext{
Author details

1 Faculty of Clinical Medicine, The University of Queensland, St Lucia, QLD 4067, Australia. ${ }^{2}$ Critical Care Research Group, The Prince Charles Hospital, Clinical Science Building, 627 Rode Rd, Chermside, QLD 4032, Australia. ${ }^{3}$ Instituto de Investigaciones Biomédicas August Pi i Sunyer (IDIBAPS), Barcelona, Spain.
}

\section{Compliance with ethical standards}

\section{Conflicts of interest}

GLB and JF have received research grants from Fisher and Paykel for other studies in the past. F\&P did not play any role in the preparation of this manuscript. There are no other relevant disclosures.

\section{Publisher's Note}

Springer Nature remains neutral with regard to jurisdictional claims in published maps and institutional affiliations.

Received: 22 October 2020 Accepted: 24 October 2020

Published online: 10 November 2020

\section{References}

1. World Health Organization (2020) WHO characterizes COVID-19 as a pandemic. https://www.who.int/emergencies/diseases/novel-coronaviru s-2019/events-as-they-happen. Accessed 3 June 2020

2. Yang X, Yu Y, Xu J, Shu H, Ja X, Liu H, Wu Y, Zhang L, Yu Z, Fang M, Yu T, Wang Y, Pan S, Zou X, Yuan S, Shang Y (2020) Clinical course and outcomes of critically ill patients with SARS-CoV-2 pneumonia in Wuhan, China: a single-centered, retrospective, observational study. Lancet Respirat Med 8:475-481

3. Grasselli G, Zangrillo A, Zanella A, Antonelli M, Cabrini L, Castelli A, Cereda D, Coluccello A, Foti G, Fumagalli R, lotti G, Latronico N, Lorini L, Merler
S, Natalini G, Piatti A, Ranieri MV, Scandroglio AM, Storti E, Cecconi M, Pesenti A (2020) Baseline characteristics and outcomes of 1591 patients infected with SARS-CoV-2 admitted to ICUs of the Lombardy region, Italy. JAMA 323:1574-1581

4. World Health Organization (2020) Transmission of SARS-CoV-2: implications for infection prevention precautions. https://www.who.int/ news-room/commentaries/detail/transmission-of-sars-cov-2-implicatio ns-for-infection-prevention-precautions. Accessed 9 Jul 2020

5. van Doremalen N, Bushmaker T, Morris DH, Holbrook MG, Gamble A, Williamson BN, Tamin A, Harcourt JL, Thornburg NJ, Gerber SI, Lloyd-Smith JO, de Wit E, Munster VJ (2020) Aerosol and surface stability of SARSCoV-2 as compared with SARS-CoV-1. N Engl J Med 382:1564-1567

6. World Health Organization (2020) Report of the WHO-China joint mission on coronavirus disease 2019 (COVID-19). https://www.who.int/publicatio ns/i/item/report-of-the-who-china-joint-mission-on-coronavirus-disea se-2019-(covid-19). Accessed 9 Oct 2020

7. Liu Y, Ning Z, Chen Y, Guo M, Liu Y, Gali NK, Sun L, Duan Y, Cai J, Westerdahl D, Liu X, Xu K, Ho K-f, Kan H, Fu Q, Lan K (2020) Aerodynamic analysis of SARS-CoV-2 in two Wuhan hospitals. Nature 582:557-560

8. Santarpia JL, Rivera DN, Herrera V, Morwitzer MJ, Creager H, Santarpia GW, Crown KK, Brett-Major D, Schnaubelt E, Broadhurst MJ, Lawler JV, Reid SP, Lowe JJ (2020) Aerosol and surface transmission potential of SARS-CoV2. medRxiv. https://doi.org/10.1101/2020.03.23.20039446

9. Bielicki JA, Duval X, Gobat N, Goossens H, Koopmans M, Tacconelli E, van der Werf S (2020) Monitoring approaches for health-care workers during the COVID-19 pandemic. Lancet Infect Dis 20(10):e261-e267. https://doi. org/10.1016/S1473-3099(20)30458-8

10. Gaeckle NT, Lee J, Park Y, Kreykes G, Evans MD, Christopher J, Hogan J (2020) Aerosol generation from the respiratory tract with various modes of oxygen delivery. Am J RespirCrit Care Med 202:1115-1124

11. Hui DS, Chow BK, Lo T, Tsang OTY, Ko FW, Ng SS, Gin T (2019) Exhaled air dispersion during high-flow nasal cannula therapy versus CPAP via different masks. Eur Respir J 53(4):1802339. https://doi.org/10.1183/13993 003.02339-2018

12. Tran $K$, Cimon K, Severn M, Pessoa-Silva CL, Conly J (2012) Aerosol generating procedures and risk of transmission of acute respiratory infections to healthcare workers: a systematic review. PLoS ONE 7:e35797

13. Leonard S, Strasser W, Whittle JS, Volakis LI, DeBellis RJ, Prichard R, Atwood CW Jr, Dungan GC II (2020) Reducing aerosol dispersion by high flow therapy in COVID-19: High resolution computational fluid dynamics simulations of particle behavior during high velocity nasal insufflation with a simple surgical mask. J Am CollEmerg Physic Open 1:578-591

14. Ahn JY, An S, Sohn Y, Cho Y, Hyun JH, Baek YJ, Kim MH, Jeong SJ, Kim JH, Ku NS, Yeom J-S, Smith DM, Lee H, Yong D, Lee Y-J, Kim JW, Kim HR, Hwang JH, Choi JY (2020) Environmental contamination in the isolation rooms of COVID-19 patients with severe pneumonia requiring mechanical ventilation or high-flow oxygen therapy. J Hosp Infect 106(3):570-576. https://doi.org/10.1016/j.jhin.2020.08.014

15. Guy T, Créac'hcadec A, Ricordel C, Salé A, Arnouat B, Bizec J-L, Langelot M, Lineau C, Marquette D, Martin F, Lederlin M, Jouneau S (2020) High-flow nasal oxygen: a safe, efficient treatment for COVID-19 patients not in an ICU. Eur Respir J. https://doi.org/10.1183/13993003.01154-2020 